\title{
BELIEFS ABOUT EMOTIONS: THE ROLE OF VALUING POSITIVE EMOTIONS IN PERSONAL WELL-BEING
}

\author{
Malathie Dissanayake ${ }^{*}$, Shanmukh Kamble ${ }^{2}$ and Appasaheb Patil ${ }^{2}$ \\ ${ }^{1}$ South Asian Institute of Technology and Medicine, Sri Lanka \\ ${ }^{2}$ Karnatak University, India
}

\begin{abstract}
Beliefs about emotions may affect individuals' emotional experiences and well-being. This research tested the assumption that specific beliefs about emotions, particularly beliefs about valuing positive emotions may be associated with individual happiness and satisfaction. Two hundred participants filled out a questionnaire examining beliefs about valuing positive emotions, affect, individual happiness and life satisfaction. Results revealed that beliefs about valuing positive emotions significantly predicted happiness and life satisfaction. Also, the link between belief about valuing positive emotions and individual happiness and the link between beliefs about valuing positive emotions and life satisfaction were partially explained by positive affect. These findings suggest the importance of examining individuals' beliefs about valuing positive emotions and the experience of positive emotions together for individuals' well-being.
\end{abstract}

Keywords: beliefs about valuing positive emotions; positive affect; well-being

\section{Introduction}

Emotions play a significant role in one's psychological well-being. Emotions are considered as the main force that organizes thoughts and behavior of individuals (Magai \& McFadden, 1996). They shape individuals' mental schemas related to their emotional experiences (Dunsmore \& Halberstadt, 1997). Individuals develop these mental schemas through the interaction with their social environment. As a result of social interactions, they may develop various beliefs and perceptions that are associated with emotions. Beliefs related to emotions can significantly influence individuals' behavior in many ways. For example, beliefs about emotions may influence individuals' perceptions about others' emotions, their reactions to other's emotions, and other important aspects of their lives including their emotional states as well as their perceptions of life.

Scholars have developed different theoretical perspectives to explain various beliefs about emotions. Some approaches have focused on their relevance to clinical and other situations. The Mentalisation theory (Fonagy \& Target, 2003), for example, claims that individuals may perceive emotions as uncontrollable, or inexplicable or dangerous and they may be unable to characterize or recognize them. It further states that these beliefs about emotions may have an impact one's ability to regulate their emotions (Swenson, Sanderson, Dulit, \& Linehan, 2001; Bateman \& Fonagy, 2004; Manser, Cooper, \& Trefusis, 2012). According to Biosocial theory, specific beliefs about emotions and the individual's propensity to avoid them may cause problems in relation to controlling and regulating emotions (Linehan, 1993). Studies on implicit beliefs about emotions have revealed that the belief that emotions are malleable is related to the use of reappraisal (Tamir, John, Srivastava, \& Gross, 2007; Schroder, Dawood, Yalch, Donnellan, \& Moser, 2015). Prior research also found that the effect of implicit beliefs about emotions on well-being outcomes such as life satisfaction and self-esteem was mediated by reappraisal implementation (De Castella et al., 2013).

Different measures have been developed to assess emotion-related beliefs. Some psychologists focused on understanding emotion-related beliefs in various contexts. For example, Halberstadt and colleagues (2013) have examined parents' beliefs about children's emotions and they have developed measures (e.g., the Parents' Beliefs About Children's Emotions Scale) to assess certain beliefs that parents have about their children's 
emotions. Then, the Beliefs About Emotion scale (Dennis \& Halberstadt, 2008) which was derived from the Parents' Beliefs About Children's Emotions Scale, was designed to measure four types of beliefs that individuals have about emotions. The Beliefs About Emotion Scale comprises four subscales: Positive Emotions are Valuable Scale, Negative Emotions are Valuable Scale, All Emotions are Dangerous Scale, and Emotions Just are Scale. Also, Manser and colleagues (2012) have designed the Beliefs About Emotions Questionnaire to assesses seven types of emotion-related beliefs.

Both positive and negative emotions have a very important role in one's life. In particular, the experience of positive emotions in everyday life seems to have valued outcomes. Research has suggested that one's positive feelings play a significant role in improving psychological growth, mental health (Fredrickson, Tugade, Waugh, \& Larkin, 2003) and happiness (Fredrickson \& Joiner, 2002). Positive emotions produce new and wide-ranging thought-action repertoires (Fredrickson \& Branigan, 2005), widen individuals' attention (Fredrickson \& Branigan, 2005; Rowe, Hirsch, \& Anderson, 2007) and develop their personal resources that enhance their life satisfaction (Cohn, Fredrickson, Brown, Mikels, \& Conway, 2009; Zhang, 2015). Previous studies have also indicated that the everyday experience of positive affect significantly influences individuals to lead a happy, healthy and long life (Danner, Snowdon, \& Friesen, 2001; Levy, Slade, Kunkel, \& Kasl, 2002; Moskowitz, 2003; Cohn, Fredrickson, Brown, Mikels, \& Conway, 2009).

With respect to the subjective well-being, theorists have focused on the interplay of three main constructs: positive affect, negative affect and life satisfaction (Myers \& Diener, 1995). Affect (positive and negative) is considered as the affective component of subjective well-being while life satisfaction is described as the cognitive component (Diener, Suh, Lucas, \& Smith, 1999). Both positive and negative affect are primary predispositions to positive and negative emotions (Watson, Clark, \& Tellegen, 1988). Life satisfaction is the overall and long-term appraisal of one's life and well-being (Suh, Diener, \& Oishi, 1998; Cakar, 2012) and it is recognized as a key element of individual well-being as well as mental health (Myers \& Diener, 1995; Diener, Suh, Lucas, \& Smith, 1999; Pavot \& Diener, 2008).

It seems that some cultures place value on positive emotions that may contribute to subjective well-being of their members. Recent research has found a significant relationship between the value of positive emotions and life satisfaction in some countries (Bastian, Kuppens, De Roover, \& Diener, 2014). Accordingly, in cultures where positive emotions are highly valued, individuals tend to experience greater satisfaction with their lives. Further, the findings revealed that the effect of the social value of positive emotions on life satisfaction was mediated by the experience of positive emotions. Thus, both individuals' perceptions of the value of positive emotions and the experience of positive emotions contribute to the higher levels of life satisfaction.

Limited attention has been paid to the beliefs related to valuing positive emotions and their impact on long-term well-being of individuals in different socio-cultural contexts. Our question concerned whether the beliefs about valuing positive emotions may be a strong predictor of life satisfaction of individuals living in a South Asian cultural context. Also, we examined how these specific beliefs would be related to individuals' satisfaction with life. We presumed that the effect of the beliefs about valuing positive emotions on life satisfaction would be mediated by the experience of positive affect.

\section{Method}

\section{Participants}

Two hundred participants ( $62 \%$ males; age range of $18-28 ; M_{\text {age }}=23$ years), from the Karnataka State in India completed a self-administered questionnaire. Of them, the majority (78\%) was Hindus and $98 \%$ was unmarried. They were recruited to the study on a voluntary basis. Participants signed an informed consent form before the data were collected. 


\section{Measures}

Beliefs about valuing positive emotions. Individuals' beliefs about valuing positive emotions were assessed with the belief that positive emotions are valuable subscale in the Beliefs about Emotion Scale (Dennis \& Halberstadt, 2008). This scale includes 10 items about beliefs about valuing positive emotions. Participants rated items on a 6 -point scale $(1=$ strongly disagree to $6=$ strongly agree $)$. Internal consistency in the current study for the scale was $\alpha=0.79$.

Positive affect. Positive affect was measured using the Positive Affect and Negative Affect scale (PANAS; Watson et al., 1988). This scale includes a number of words that describe different feelings. Ratings were made on a 5-point Likert scale ranging from 1 (very slightly or not at all) to 5 (extremely). In the current sample, alpha reliability for positive affect was $\alpha=.71$.

Subjective Happiness. Individual happiness was measured using the Subjective Happiness Scale (SHS; Lyubomirsky \& Lepper, 1999). This scale consists of 4 items. Participants rated items using a 4-point scale. The item one was rated on a scale ranging from 1 (not a very happy person) to 7 (a very happy person). The item two was rated on a scale ranging from 1 (less happy) to 7 (more happy). Items 3 and 4 were rated using a scale ranging from 1 (not at all) to 7 (great deal). Internal consistency in the current study was $\alpha=.63$.

Life Satisfaction. Individuals' general sense of life fulfillment was assessed with the 5-item Satisfaction with Life Scale (SWLS; Diener, Emmons, Larsen, \& Griffin, 1985). Participants used a 7-point scale ranging from 1 (strongly disagree) to 5 (strongly agree) to rate their agreement with the statements such as "If I could live my life over, I would change almost nothing", and "I am satisfied with my life." The scale had adequate reliability $(\alpha=.70)$.

\section{Results}

\section{The Relationship between Beliefs about Valuing Positive Emotions and Life Satisfaction}

Correlational analyses were conducted to examine the relationships among main variables: beliefs about valuing positive emotions, positive affect, individual happiness and satisfaction with life. As expected, there was a significant correlation between beliefs about valuing positive emotions and life satisfaction $(r(200)=.40, p<$ .01 ), indicating that individuals who rated high on beliefs about valuing positive emotions were more satisfied with their lives. Beliefs about valuing positive emotions was also correlated with individual happiness $(r(200)=$ $.39, p<.01)$, suggesting that individuals who rated high on beliefs about valuing positive emotions were happier. Further, beliefs about valuing positive emotions was significantly correlated with positive affect $(r(200)=.34$, $p<.01)$. That is, those who strongly believe that positive emotions are valuable seem to experience more positive affect. Moreover, there were significant correlations between positive affect and satisfaction with life $r(200)=.32, p<.01$ as well as positive affect and individual happiness $(r(200)=.33, p<.01)$ (see Table 1$)$.

Table 1: Inter-correlations among beliefs about valuing positive emotions, positive affect, happiness and life satisfaction

\begin{tabular}{llll}
\hline Measures & Positive affect & $\begin{array}{l}\text { Beliefs about valuing } \\
\text { positive emotions }\end{array}$ & Life satisfaction \\
\hline Beliefs about valuing positive emotions & $.34^{* *}$ & \\
Life satisfaction & $.32^{* *}$ & $.40^{* *}$ & $.53^{* *}$ \\
Subjective happiness & $.33^{* *}$ & $.39^{* *}$ &
\end{tabular}




\section{The Mediating Effect of Positive Affect}

Hierarchical regression analysis was conducted to examine the effect of beliefs about valuing positive emotions on satisfaction with life as well as individual happiness. Secondly, we assessed whether the link between beliefs about valuing positive emotions and satisfaction with life was mediated by positive affect. Thirdly, we tested whether the link between beliefs about valuing positive emotions and individual happiness was mediated by positive affect. Regression analysis was employed using the enter method. As expected, the belief that positive emotions are valuable was a significantly predictor of life satisfaction. The results of the mediational analysis revealed that positive affect was a significant mediator between the belief that positive emotions are valuable and life satisfaction. When adding positive affect in the third step, the relationship between the belief that positive emotions are valuable and life satisfaction was reduced $(r=.46)$. Thus, positive affect partially mediated the link between the belief that positive emotions are valuable and life satisfaction (see Table 2).

Table 2: Hierarchical Regression Models with Mediating Effect of Positive Affect in the Link between Beliefs about Valuing Positive emotions and Life Satisfaction $(n=200)$

Life Satisfaction

$\begin{array}{lll}B & S E & B\end{array}$

Predictors

Step 1

Beliefs about valuing positive emotions

$.56 \quad .09 \quad .40 * * *$

Positive Affect

Step 2

Beliefs about valuing positive emotions

Life Satisfaction

Step 3

Beliefs about valuing positive emotions

$\begin{array}{lll}.46 & .10 & .32 * * *\end{array}$

Positive Affect

.45 .14

$.22 * *$

$\mathrm{R}^{2}=.16$ for step $1 ; \Delta \mathrm{R}^{2}=.20$ for step 3

$* * p<.01, * * * p<.001$

A commonality analysis was conducted to determine the amount of predicted variance that was shared among and unique to the belief that positive emotions are valuable and positive affect variables. Results indicated that the two variables in the regression shared $7 \%$ of the variance in life satisfaction. The beliefs about valuing positive emotions uniquely explained $9 \%$ of the variance and positive affect accounted for $4 \%$ of the variance.

The same regression analysis was carried out to test the effect of beliefs about valuing positive emotions on individual happiness and the mediating role of positive affect in the above relationship. The belief that positive emotions are valuable significantly predicted individual happiness as well as positive affect. With the addition of mediating variable (positive affect) in hierarchical regression, the link between the belief that positive emotions are valuable and individual happiness was reduced $(r=.46)$ (see Table 3). Hence, the relationship 
between the belief that positive emotions are valuable and individual happiness was partially mediated by positive affect.

Table 3: Hierarchical Regression Models with Mediating Effect of Positive Affect in the link between Beliefs about valuing positive emotions and Subjective Happiness $(n=200)$

Subjective Happiness

\begin{tabular}{|c|c|c|c|}
\hline & $B$ & $S E$ & $B$ \\
\hline \multicolumn{4}{|l|}{ Predictors } \\
\hline \multicolumn{4}{|l|}{ Step 1} \\
\hline $\begin{array}{l}\text { Beliefs about valuing positive } \\
\text { emotions }\end{array}$ & .56 & .09 & $.39 * * *$ \\
\hline & \multicolumn{3}{|c|}{ Positive Affect } \\
\hline \multicolumn{4}{|l|}{ Step 2} \\
\hline $\begin{array}{l}\text { Beliefs about valuing positive } \\
\text { emotions }\end{array}$ & .23 & .05 & $.34 * * *$ \\
\hline & \multicolumn{3}{|c|}{ Subjective Happiness } \\
\hline \multicolumn{4}{|l|}{ Step 3} \\
\hline $\begin{array}{l}\text { Beliefs about valuing positive } \\
\text { emotions }\end{array}$ & .46 & .10 & $.32^{* * *}$ \\
\hline Positive affect & .47 & .14 & $.22 * *$ \\
\hline
\end{tabular}

In order to determine the amount of predicted variance explained by the predictor variables, a commonality analysis was conducted. It was found that the two variables shared $7 \%$ of the variance in subjective happiness. Beliefs about valuing positive emotions accounted for $9 \%$ of the variance and positive affect explained $4 \%$ of the variance.

\section{Discussion}

Individuals' beliefs about emotions seem to have significant impact on their happiness and well-being. Findings of this study revealed that the effect of the beliefs about valuing positive emotions on individuals' life satisfaction was significant. Also, there was evidence that the beliefs about valuing positive emotions had significant effect on subjective happiness. This suggests that individuals with strong beliefs that positive emotions are valuable are happier and more satisfied with their lives. Prior research has indicated that beliefs about emotions are associated with happiness and life satisfaction (Danner, Snowdon, \& Friesen, 2001; Levy, Slade, Kunkel, \&Kasl, 2002; Moskowitz, 2003; Cohn, Fredrickson, Brown, Mikels, \& Conway, 2009). Our findings also are similar to the results of other studies. There may be several reasons for the link between the beliefs about value of positive emotions and life satisfaction or subjective well-being. One is there may be a tendency to experience positive emotions more willingly, when individuals believe that others around them will react to their emotions in a positive manner (Evers, Fischer, Rodriguez Mosquera, \& Manstead, 2005). The 
other is cultures that place value on positive emotions may arrange conditions that encourage the experience of positive emotions. As a result, the members of such cultures may feel greater levels of life satisfaction.

This research also tested the role of positive affect in the relationship between beliefs about valuing positive emotions and life satisfaction as well as individual happiness. Beliefs about valuing positive emotions was a significant predictor of positive affect, indicating that individuals with strong beliefs about value of positive emotions experience more positive affect. Findings also revealed that the effect of beliefs about valuing positive emotions on life satisfaction was partially mediated by positive affect. That is, the relationship between the beliefs that positive emotions are valuable and satisfaction with life is partly due to the experience of positive affect. Further, positive affect was a significant mediator of beliefs about positive valuing positive emotions and subjective happiness. Accordingly, the experience of positive affect has a relevant role in this relationship. Cross-cultural studies have suggested that societies where emotions are corresponding with their cultural values, individuals are more likely to feel positive emotions more frequently (Boiger, Mesquita, Uchida, \& Barrett, 2013). There is evidence that frequent experience of positive emotions can significantly contribute to one's subjective well-being. Positive emotions are known to enhance social and psychological resources like individuals' satisfaction with life (Fredrickson, 2001; Fredrickson, 2013). Prior research has also provided evidence for the impact of experiencing more positive affectivity on individuals' satisfaction with life (Singh \& Jha, 2008; Lucas \& Diener, 2008).

These findings are consistent with the prior research on the effect of social value of positive emotions and satisfaction with life in some cultures. Individuals seem to experience greater satisfaction with life in countries where positive emotions are considered as important (Bastian, Kuppens, De Roover, \& Diener, 2014). We found stronger support for the mediating effect of positive affect in the link between the beliefs about valuing positive emotions and life satisfaction. It seems that cultures may have an impact on individuals' emotions via developing cultural values and norms for their emotional experiences and expressions (Fischbach, 2009). People across cultures may place value on different emotions. For example, some cultures (e.g., American and Australian cultures) tend to highly value positive emotions (Fischbach, 2009). This research included a sample of native Indians lived in a state in the south western region of India. Our findings provide further evidence that cultural values related to positive emotions strongly influence the experience of positive emotions and the sense of fulfillment with life.

A limitation of this work is that, it used a convenience sample of 200 individuals aged from 18-28. Therefore, it may limit the generalizability of the findings. Overall, our results suggest that believing that positive emotions are valuable and the experience of these emotions significantly contribute to personal well-being. Future research could focus on understanding similarities or differences in pathways linking beliefs about valuing positive emotions and satisfaction with life in other age groups living in these socio-cultural contexts.

\section{Reference}

Bastian, B., Kuppens, P., De Roover, K., \&Diener, E. (2014). Emotion, 14(4), 639-645.

doi: $10.1037 / \mathrm{a} 0036466$

Bateman, A. W., \& Fonagy, P. (2004). Mentalization-Based Treatment of BPD. Journal of Personality Disorders, 18, 36-51. http://dx.doi.org/10.1521/pedi.18.1.36.32772

Boiger, M., Mesquita, B., Uchida, Y., \& Barrett, L. F. (2013). Condoned or condemned: The situational affordance of anger and shame in the United States and Japan. Personality and Social Psychology Bulletin, 39, 540-553. doi:10.1177/0146167213478201

Çakar, F. S. (2012). The relationship between the self-efficacy and life satisfaction of young adults. International Education Studies, 5, 123-130.

Cohn, M., Fredrickson, B., Brown, S., Mikels, J., Conway, A. (2009). Happiness unpacked: Positive emotions increase life satisfaction by building resilience, Emotion, 9, 361-368. 
Danner, D. D., Snowdon, D. A., \& Friesen, W. V. (2001). Positive emotions in early life and longevity: Findings from the Nun Study. Journal of Personality and Social Psychology, 80, 804-813.

De Castella, C., Golding, P., Jazaieri, H., Ziv, M., Dweck, C. S., \& Gross, J. J. (2013). Beliefs about_Emotion: Links to Emotion Regulation, Well-Being, and Psychological Distress. Basic and Applied_Social Psychology, 35, 497-505. http://dx.doi.org/10.1080/01973533.2013.840632

Dennis, P. A., \& Halberstadt, A. G. (n.d.).The beliefs about emotion scale. Unpublished manuscript.

Diener, E., Emmons, R. A., Larsen, R. J., \& Griffin, S. (1985). The satisfaction with life scale. Journal of Personality Assessment, 49(1), 71-75.

Diener, E., Suh, E. M., Lucas, R. E., \& Smith, H. L. (1999). Subjective well-being: Three decades of progress. Psychological Bulletin, 125(2), 276-302.

Dunsmore, J. C., \& Halberstadt, A. G. (1997). How does family emotional expressiveness affect children's schemas? In K. C. Barrett (Ed.) The Communication of Emotion: Current Research from Diverse Perspectives, New Directions for Child Development, 77, 45-68. San Francisco: Jossey-Bass.

Evers, C., Fischer, A. H., Rodriguez Mosquera, P. M., \& Manstead, A. S. (2005). Anger and social appraisal: A "spicy" sex difference? Emotion, 5, 258-266.

Fischbach, A. (2009), Cross-national, cross-cultural research of emotions at work: A review and some recommendations. In C. E. J. Härtel, N. M. Ashkanasy, \& W. J. Zerbe (Eds.), Emotions in groups, organizations, and cultures, Vol. 5. (pp. 299-325). UK: JAI Press.

Fonagy, P., \& Target, M. (2003). Psychoanalytic Theories: Perspectives from Developmental Psychopathology. London: Whurr Publishers Limited.

Fredrickson, B. L. (2001). The role of positive emotions in positive psychology: The Broaden-and-Build theory of positive emotions. American Psychologist, 56(3), 218-226.

Fredrickson, B. L. (2013). Positive emotions broaden and build. Advances on Experimental Social Psychology, 47, 1-53.

Fredrickson, B. L., \& Joiner, T. (2002). Positive emotions trigger upward spirals toward emotional well-being. Psychological Science, 13, 172-175.

Fredrickson, B. L., \& Branigan, C. A. (2005). Positive emotions broaden the scope of attention and thoughtaction repertoires. Cognition and Emotion, 19, 313-332.

Fredrickson, B. L., Tugade, M. M, Waugh, C. E., \&Larkin, G. (2003). What good are positive emotions in crises? A prospective study of resilience and emotions following the terrorist attacks on the United States on September 11th, 2001. Journal of Personality and Social Psychology, 84, 365-376.

Halberstadt, A. G., Dunsmore, J. C., Bryant, A. J., Parker, A. E., Beale, K. S., \& Thompson, J. A. (2013). Development and Validation of the Parents' Beliefs about Children's Emotions Questionnaire. Psychological Assessment, 25(4), 1195-1210. http://doi.org/10.1037/a0033695

Levy, B. R., Slade, M. D., Kunkel, S. R., \& Kasl, S. V. (2002). Longevity increased by positive self-perceptions of aging. Journal of Personality and Social Psychology, 83, 261-270.

Linehan, M. M. (1993). Cognitive-Behavioral Treatment for Borderline Personality Disorder. New York: Guilford Press.

Lucas, R. E., \& Diener, E. (2008). Personality and subjective well-being. In O. P. John, R. W. Robins, \& L. A. Pervin (Eds.), Handbook of personality: Theory and research ( $3^{\text {rd }}$ ed.). (pp.795-814). New York, NY: Guilford.

Lyubomirsky, S., \& Lepper, H. (1999). A measure of subjective happiness: Preliminary reliability and construct validation. Social Indicators Research, 46, 137-155.

Magai, C., \& McFadden, S. H. (1996). Handbook of emotion, adult development, and aging. San California: Academic Press.

Manser, R., Cooper, M., \& Trefusis, J. (2012). Beliefs about Emotions as a Metacognitive Construct: Initial Development of a Self-Report Questionnaire Measure and Preliminary Investigation in Relation to Emotion Regulation. Clinical Psychology and Psychotherapy, 19, 235-246. http://dx.doi.org/10.1002/cpp.745

Moskowitz, J. T. (2003). Positive affect predicts lower risk of AIDS mortality. Psychosomatic Medicine, 65, 620-626.

Myers, D. G., \&Diener, E. (1995). Who is happy? Psychological Science, 6(1), 10-19. 
http://www3.interscience.wiley.com/cgi-bin/fulltext/119964768/PDFSTART

Pavot, W., \& Diener, E. (2008). The Satisfaction with Life Scale and the emerging construct of life satisfaction. The Journal of Positive Psychology, 3, 137-152. http://dx.doi.org/10.1080/17439760701756946

Rowe, G., Hirsh, J. B., \& Anderson, A. K. (2007). Positive affect increases the breadth of attentional selection. Proceedings of the National Academy of Sciences, USA, 104,383-388.

Schroder, H. S., Dawood, S., Yalch, M. M., Donnellan, M. B., \& Moser, J. S. (2015). The Role of Implicit Theories in Mental Health Symptoms, Emotion Regulation, and Hypothetical Treatment Choices in College Students. Cognitive Therapy and Research, 39(2), 120-139. doi: 10.1007/s10608-014-9652-6

Singh, K. \& Jha, S. D. (2008).Positive and negative affect, and grit as predictors of happiness and life satisfaction. Journal of the Indian Academy of Applied Psychology, 34, 40-45.

Suh, E., Diener, E., \& Oishi, S. (1998). The shifting basis of life satisfaction judgments across cultures: Emotions versus norms. Journal of Personality and Social Psychology, 74(2), 482-493. doi:10.1037/00223514.74.2.482

Swenson, C. R., Sanderson, C., Dulit, R. A., \& Linehan, M. M. (2001). The Application of Dialectical Behavior Therapy for Patients with Borderline Personality Disorder on Inpatient Units. The Psychiatric Quarterly, 72, 307-324. http://dx.doi.org/10.1023/A:1010337231127

Tamir, M., John, O. P., Scrivastava S., \& Gross, J. J. (2007). Implicit Theories of Emotion: Affective and Social Outcomes across a Major Life Transition. Journal of Personality and Social Psychology, 92, 731-744.

http://dx.doi.org/10.1037/0022-3514.92.4.731

Watson, D., Clark, L. A., \& Tellegen, A. (1988). Development and validation of brief measures of positive and negative affect: The PANAS scales. Journal of Personality and Social Psychology, 54(6), 1063-1070. doi:10.1037/0022-3514.54.6.1063

Zhang, R. (2015). Positive Affect and Self-Efficacy as Mediators Between Personality and Life Satisfaction in Chinese College Freshmen, Journal of Happiness Studies, 1-15. 